\title{
Reference values for methacholine reactivity (SAPALDIA study)
} Pierre-Yves Jayet ${ }^{\dagger 1}$, Christian Schindler ${ }^{\dagger 2}$, Nino Künzli ${ }^{2,3}$, JeanPierre Zellweger ${ }^{1}$, Otto Brändli ${ }^{4}$, André Paul Perruchoud ${ }^{5}$, Roland Keller ${ }^{6}$, Joel Schwartz ${ }^{7}$, Ursula Ackermann-Liebrich ${ }^{2}$, Philippe Leuenberger*1 and SAPALDIA team

Address: ${ }^{1}$ Service of Pulmonology, University Hospital Lausanne, Switzerland, ${ }^{2}$ Institute of Social and Preventive Medicine, University of Basle, Switzerland, ${ }^{3}$ Division of Environmental Health, University of Southern California, USA, ${ }^{4}$ Zürcher Höhenklinik Wald, Switzerland, ${ }^{5}$ Department of Internal Medicine, University Hospital of Basle, Switzerland, ${ }^{6}$ Klinik Barmelweid, Aarau, Switzerland and ${ }^{7}$ Department of Environmental Health, Harvard School of Public Health, USA

Email: Pierre-Yves Jayet - pierre-yves.jayet@chuv.hospvd.ch; Christian Schindler - christian.schindler@unibas.ch; Nino Künzli - kuenzli@usc.edu; Jean-Pierre Zellweger - zellwegerjp@swissonline.ch; Otto Brändli - otto.braendli@zhw.ch; André Paul Perruchoud - aperruchoud@uhbs.ch; Roland Keller - kellermed@swissonline.ch; Joel Schwartz - jschwrtz@hsph.harvard.edu; Ursula Ackermann-Liebrich - ursula.ackermann-liebrich@unibas.ch; Philippe Leuenberger* - philippe.leuenberger@chuv.hospvd.ch

* Corresponding author †Equal contributors

Published: 04 November 2005

Respiratory Research 2005, 6:131 doi:10.1186/1465-992I-6-131
Received: 03 June 2005

Accepted: 04 November 2005

This article is available from: http://respiratory-research.com/content/6/I//3 |

(c) 2005 Jayet et al; licensee BioMed Central Ltd.

This is an Open Access article distributed under the terms of the Creative Commons Attribution License (http://creativecommons.org/licenses/by/2.0), which permits unrestricted use, distribution, and reproduction in any medium, provided the original work is properly cited.

\begin{abstract}
Background: The distribution of airway responsiveness in a general population of non-smokers without respiratory symptoms has not been established, limiting its use in clinical and epidemiological practice. We derived reference equations depending on individual characteristics (i.e., sex, age, baseline lung function) for relevant percentiles of the methacholine two-point doseresponse slope.
\end{abstract}

Methods: In a reference sample of 1567 adults of the SAPALDIA cross-sectional survey (199I), defined by excluding subjects with respiratory conditions, responsiveness during methacholine challenge was quantified by calculating the two-point dose-response slope ( $\left.\mathrm{O}^{\prime} \mathrm{Connor}\right)$. Weighted $\mathrm{LI}$-regression was used to estimate reference equations for the $95^{\text {th }}, 90^{\text {th }}, 75^{\text {th }}$ and $50^{\text {th }}$ percentiles of the two-point slope.

Results: Reference equations for the $95^{\text {th }}, 90^{\text {th }}, 75^{\text {th }}$ and $50^{\text {th }}$ percentiles of the two-point slope were estimated using a model of the form a $+b^{*} A g e+c^{*} F E V_{1}+d^{*}\left(F_{E V}\right)^{2}$, where FEV corresponds to the pre-test (or baseline) level of FEV . For the central half of the FEV, distribution, we used a quadratic model to describe the dependence of methacholine slope on baseline FEV . For the first and last quartiles of $F E V_{1}$, a linear relation with $F E V_{1}$ was assumed (i.e., $d$ was set to $0)$. Sex was not a predictor term in this model. A negative linear association with slope was found for age. We provide an Excel file allowing calculation of the percentile of methacholine slope of a subject after introducing age - pre-test $\mathrm{FEV}_{1}$ - and results of methacholine challenge of the subject.

Conclusion: The present study provides equations for four relevant percentiles of methacholine two-point slope depending on age and baseline $\mathrm{FEV}_{1}$ as basic predictors in an adult reference population of non-obstructive and non-atopic persons. These equations may help clinicians and epidemiologists to better characterize individual or population airway responsiveness. 


\section{Background}

Description of normal airway responsiveness in a general population is a recent concept [1]. However its use in clinic or in epidemiological studies is limited by the lack of established norms (as percentiles) of the distribution of airway reactivity [2] according to the age, sex and airway caliber of the subjects [3].

The conventional method to measure bronchial responsiveness is to perform a bronchochallenge test where $\mathrm{FEV}_{1}$ is measured at increasing levels of methacholine [4] up to a maximal dose of $2 \mathrm{mg}$ and to evaluate the resulting dose-response curve. Results of the test are usually expressed by an index of responsiveness, the provocating dose (PD20) or concentration (PC20) producing a 20\% fall of $\mathrm{FEV}_{1}$. A subject is defined to be hyperreactive if, at any of the methacholine levels tested, his/her FEV falls $_{1}$ below $80 \%$ of the baseline value. In epidemiological studies, however, the concept of hyperreactivity has substantial limitations since the majority of subjects do not reach the critical threshold level so that their degree of responsiveness cannot be defined in terms of a critical dose [5].

In order to obtain a simple index of non-specific airway reactivity for every subject (hyperreactive or normal), O'Connor et al [6] defined the slope of the dose-response curve as the ratio between percent decline of $\mathrm{FEV}_{1}$ (from the post-saline value to the value measured after the final methacholine dose administered) and the final cumulative dose of methacholine. For both asthmatic and normal people this simple dose-response slope provides a good summary of each subject's dose-response curve [7].

The distribution of hyperreactivity or of airway responsiveness in a general population sample has been described in several studies $[6,8,9]$. For tests performed with methacholine or with histamine, non-specific airway responsiveness shows a unimodal skewed distribution. Although asthmatic subjects tend to lie in the "reactive" tail of the distribution, there is a considerable overlap between the distributions of asthmatic and non-asthmatic subjects. Some authors suggest that this unimodal distribution reflects several overlapping clinical states between normal subjects and symptomatic asthmatics [10]. However, apart from clinical state many individual predictive factors influence the degree of bronchial responsiveness. Whereas age has been investigated in many studies $[2,5,11-16]$, the exact influence of aging on reactivity is still not clear. Its estimated effect appears to depend on whether other possible confounding variables such as baseline lung function or smoking status are simultaneously taken into account. Sex appears to be another important predictive factor: women seem to be more reactive than men $[5,12,14-16]$, but adjusting for possible confounding factors may explain some of this difference.
Pre-test $\mathrm{FEV}_{1}$ is considered as a major parameter influencing bronchial responsiveness $[11,12,14-16]$. However many other potential variables appear to play a role, such as smoking status $[11,13-15,17]$, geographic characteristics [2,11], atopic status [14-16], occupational exposure to inhalation irritants [18], presence of chronic respiratory conditions or prior asthma [19], or recent upper airway infection [19]. These findings indicate that bronchial responsiveness, as described by PD20, PC20 or doseresponse slope, may be influenced by a wide range of factors that in turn, may substantially affect its interpretation.

Data from the asymptomatic never smoking participants of the SAPALDIA cross-sectional study (1991) have already been used by Brändli [20,21] to derive reference equations for mean values and lower limits of normal of spirometric lung function. In this paper we use data of the methacholine challenge test from a selected sample of "normal" participants of the SAPALDIA sample to establish reference equations for some important percentiles of methacholine slope depending on important individual characteristics (i.e., sex, age and baseline lung function).

\section{Methods}

SAPALDIA (Swiss Study on Air Pollution and Lung Diseases in Adults) is a multicenter study designed to investigate the relationship between exposure to air pollutants and respiratory symptoms or diseases. The eight study areas participating in the project were chosen to represent the variety of environmental conditions found in Switzerland concerning geography, climate, degree of urbanisation and air pollution. The study was approved by the institutional review board for human investigations of the different areas. In the cross-sectional part performed in 1991 , a random sample of adults 18 to 60 years old were invited to take part in the study. 9651 subjects were included in the study, representing 59\% of all eligible subjects. Health assessment included a detailed questionnaire, computer-based spirometric tests, methacholine bronchial challenge and skin allergy tests to 8 inhalative allergens. Details on the methodology of these assessments are given elsewhere [22].

Spirometry measurements were done using a Sensor-Medics 2200 pulmonary function system SP (Bilthoven, The Netherlands). This is an open sensor device which meets the quality criteria of the American Thoracic Society. The Sensor-Medics spirometer displays an error code after each forced expiration to inform the technician about the acceptability of the maneuver and the reproducibility between the trials using the standard quality criteria defined by the American Thoracic Society [23]. The trials were recorded electronically on a personal computer as they were done. Calibration was done at least once daily, 


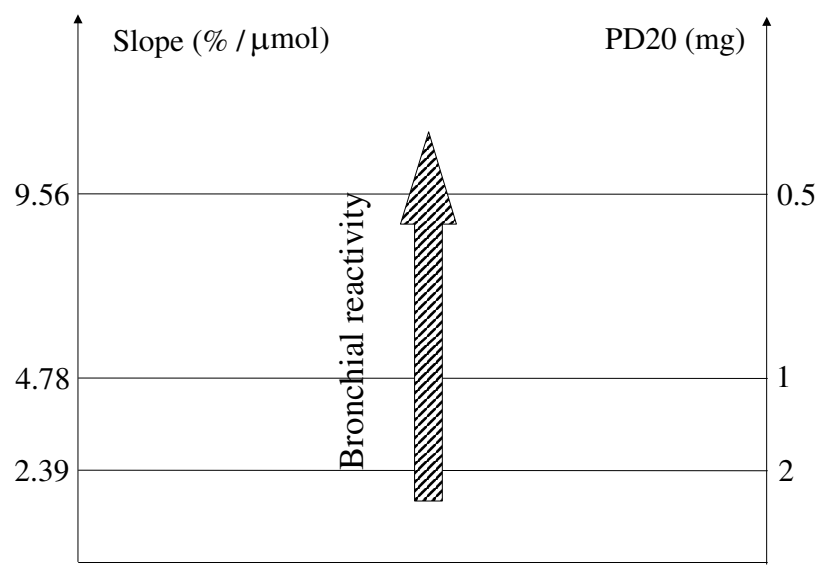

Figure I

Graphic representation of the relationship between the two-point dose response slope and PD20. This figure shows the relationship between the two-point dose response slope and PD20. The horizontal line drawn at a slope of $2.39 \%$ decrease $/ \mu \mathrm{mol}$ represents the "cut-off" threshold commonly used to define bronchial hyperreactivity (20\% decrease of FEV, after a cumulative methacholine dose of $\leq 2 \mathrm{mg}$ ).

using a 3-liter syringe. All the spirometry technicians were trained together according to a standardized protocol and were tested on volunteers [24]. Each of the following criteria was sufficient for excluding a subject from the methacholine test: a) a baseline $\mathrm{FEV}_{1}$ / FVC ratio of less than $80 \%$ of the ECCS-norm [25], b) a baseline $\mathrm{FEV}_{1}$ of less than $70 \%$ of the ECCS-norm, c) pregnancy or breast feeding, d) a myocardial infarction within the three months preceding the SAPALDIA examination, e) severe heart failure under treatment, $f$ ) treatment with $\beta$-blockers including eye-drops, g) refusal to participate. These exclusions and the requirement of having complete and valid data on lung function and bronchial responsiveness reduced the sample size to 6942 . Non-specific bronchial reactivity was tested using methacholine chloride (Provocholine ${ }^{\circledast}$, Roche, Nutley, New Jersey, USA) prepared in 0.39, 1.56, 6.25 , and $25.0 \mathrm{mg} / \mathrm{ml}$ solutions in a phosphate buffer without phenol. Increasing concentrations of methacholine were administered through an aerosol dosimeter (Mefar MB3, Bovezzo, Italy) up to a cumulative dose of 2 $\mathrm{mg}(8.37 \mu \mathrm{mol})$. With each inhalation, approximately $0.01 \mathrm{ml}$ was delivered to the subject. The first dose inhaled by the subject was a saline control. The schedule was then 4 inhalations of methacholine of $0.39 \mathrm{mg} / \mathrm{ml}$ (total dose $0.016 \mathrm{mg}$ ), 3 inhalations of $1.56 \mathrm{mg} / \mathrm{ml}$ (cumulative dose $0.062 \mathrm{mg}$ ), 3 inhalations of $6.25 \mathrm{mg} / \mathrm{ml}$ (cumulative dose
$0.25 \mathrm{mg}$ ), 3 inhalations of $25 \mathrm{mg} / \mathrm{ml}$ (cumulative dose 1 $\mathrm{mg}$ ), and 4 inhalations of $25.0 \mathrm{mg} / \mathrm{ml}$ (total cumulative dose $2 \mathrm{mg}$ ). If a decrease in $\mathrm{FEV}_{1}$ of more than $10 \%$ from the baseline level occurred at any intermediate point of the test, smaller increments (i.e., halving the doses and doubling the number of inhalations) were introduced. Testing continued until the final dose of $2 \mathrm{mg}$ was administered or until $\mathrm{FEV}_{1}$ had fallen by $20 \%$ or more. Under this protocol the cumulative doses of methacholine converted in micromoles at each level were 0, 0.065, 0.26, $1.05,4.18$, and 8.37. At each level, the subjects were asked to inhale slowly from their functional residual capacity up to their vital capacity. The subjects were instructed to keep a full inspiration for 4 seconds before a slow normal exhalation. After each dose level of methacholine, 2 forced expiratory maneuvers were performed at 1 and 2 minutes after the end of the methacholine inhalation and the best of the two $\mathrm{FEV}_{1}$ values was considered [26].

Methacholine responsiveness was quantified by calculating the two-point dose-response slope as defined by O'Connor [6]. Slope is defined as the percentage of decline of $\mathrm{FEV}_{1}$ from the post-saline value to the value measured after the final methacholine dose administered divided by the final cumulative methacholine dose administered. Figure 1 provides a schematic diagram illustrating the relationship between the two-point dose response slope (expressed in \% decline of $\mathrm{FEV}_{1}$ divided by the final cumulative methacholine dose administered) and PD20 (provocating dose in mg producing a $20 \%$ fall of $\mathrm{FEV}_{1}$ ). The figure demonstrates that higher reactivity is indicated by a higher value of slope. The horizontal line drawn at a slope of $2.39 \%$ decrease/ $\mu \mathrm{mol}$ represents the threshold commonly used to define bronchial hyperreactivity $\left(20 \%\right.$ decrease of $\mathrm{FEV}_{1}$ after a cumulative methacholine dose of $\leq 2 \mathrm{mg}$ ).

Of the participants who performed the methacholine test, only 1567 were included in the reference sample after applying the following exclusion criteria: a) current or former smoking: (i.e., having smoked 20 or more packs of cigarettes or more than $360 \mathrm{~g}$ of tobacco); b) a prior diagnosis of asthma or report of symptoms related to asthma or bronchitis (i.e., wheezing in the last 12 months and/or shortness of breath at rest in the last 12 months and/or nocturnal attacks of shortness of breath in the last 12 months and/or attacks of asthma in the last 12 months and/or current asthma medication and/or cough or phlegm on most days of at least three months of the year); c) atopy: defined by the presence of at least one positive reaction to the eight inhalant allergens tested in a skin prick test (subjects with missing results in this test were also excluded); d) recent respiratory infection (i.e., anamnesis of a respiratory infection within three weeks prior to the methacholine test). 
Table I: Definition of the study sample, SAPALDIA cross-sectional study, I99 I

\begin{tabular}{|c|c|c|c|}
\hline & Men & Women & Total \\
\hline Whole SAPALDIA sample & $4743(100 \%)$ & $4908(100 \%)$ & 9651 (100\%) \\
\hline $\begin{array}{l}\text { - subjects with incomplete data on lung function and bronchial } \\
\text { responsiveness* }\end{array}$ & $3446(72.7 \%)$ & $3496(71.2 \%)$ & $6942(71.9 \%)$ \\
\hline - current or former smokers & $1278(26.9 \%)$ & $1770(36.1 \%)$ & $3048(31.6 \%)$ \\
\hline $\begin{array}{l}\text { - subjects with a prior diagnosis of asthma or symptoms related to asthma } \\
\text { or bronchitis }\end{array}$ & $1052(22.2 \%)$ & $1428(29.1 \%)$ & $2480(25.7 \%)$ \\
\hline - subjects with a positive or missing skin test & $733(15.5 \%)$ & $1107(22.6 \%)$ & $1840(19.1 \%)$ \\
\hline - subjects with recent respiratory infection & $612(12.9 \%)$ & $955(19.5 \%)$ & $1567(16.2 \%)$ \\
\hline Total of the study sample & $612(12.9 \%)$ & 955 (19.5\%) & 1567 (16.2\%) \\
\hline
\end{tabular}

Weighted L1-regression was used to estimate percentile functions. This method consists of finding the model parameters which minimize a given weighted sum of absolute residual values. For instance, estimating the model for the $75^{\text {th }}$ percentile is achieved by assigning the absolute values of positive residuals three times the weight of the absolute values of negative residuals. In general, if the m-th percentile is to be estimated, absolute values of positive residuals are given a weight proportional to $1 /(100-\mathrm{m})$ and absolute values of negative residuals a weight proportional to $1 / \mathrm{m}$. Details of this method are described elsewhere [27-29]. To test whether a given model could be improved by adding an additional predictor term, we defined a dichotomous variable $U$ taking the value 1 for observations with methacholine slopes exceeding the respective percentile estimates and the value 0 for all other observations. A logistic regression model incorporating the covariate part of the underlying percentile model along with the additional predictor term was then computed. If the additional predictor term was significant then it was added to the percentile model. These methods have already been applied in a similar context to estimate percentile equations for lung function [21].
We tested the performance of this approach in identifying asthmatics using the $90^{\text {th }}$ percentile of slope as threshold in subjects who answered positively to the double question: "Have you ever had asthma? Was this confirmed by a doctor?" and performed methacholine test (i.e. fulfilled initial inclusion criteria mentioned above). For both men and women of this subsample, the percentage of subjects whose slopes exceeded this threshold was compared to the percentage of subjects usually defined as hyperreactive (i.e., with a positive response to the methacholine test based on a fall of $20 \%$ of $\mathrm{FEV}_{1}$ during the test).

\section{Results}

The different stages leading to the selection of the reference sample are described in Table 1. Only 1567 persons, representing $20.9 \%$ of all participants of the methacholine bronchial challenge fulfilled all criteria. The major part of subjects excluded were current or former smokers.

Characteristics of the study population are provided in Table 2. It included a higher proportion of women $(60.9 \%)$ than in the whole methacholine test sample

Table 2: Distribution of basic predictor variables in the reference sample, SAPALDIA cross-sectional study, I99 I

\begin{tabular}{|c|c|c|c|}
\hline & Men $(n=612)$ & Women $(n=955)$ & Entire reference sample $(n=1567)$ \\
\hline$<30$ yrs & $31.7 \%$ & $20.8 \%$ & $25.1 \%$ \\
\hline $30-40$ yrs & $24.8 \%$ & $20.5 \%$ & $22.2 \%$ \\
\hline $40-50$ yrs & $25.5 \%$ & $27.9 \%$ & $26.9 \%$ \\
\hline$\geq 50$ yrs & $18.0 \%$ & $30.8 \%$ & $25.8 \%$ \\
\hline Height, mean (SD) & I76.I (6.7) & $163.5(6.5)$ & $168.4(9.0)$ \\
\hline Weight, mean (SD) & $75.2(10.2)$ & $61.6(10.6)$ & $66.9(12.4)$ \\
\hline $\mathrm{FEV}_{1}$, mean (SD) & $4.33(0.67)$ & $3.10(0.54)$ & $3.58(0.84)$ \\
\hline PD20 prevalence* & $4.4 \%$ & $14.6 \%$ & $10.6 \%$ \\
\hline
\end{tabular}

* PD20 prevalence denotes prevalence of subjects with a fall of $20 \%$ or more in $\mathrm{FEV}$, during the methacholine test 


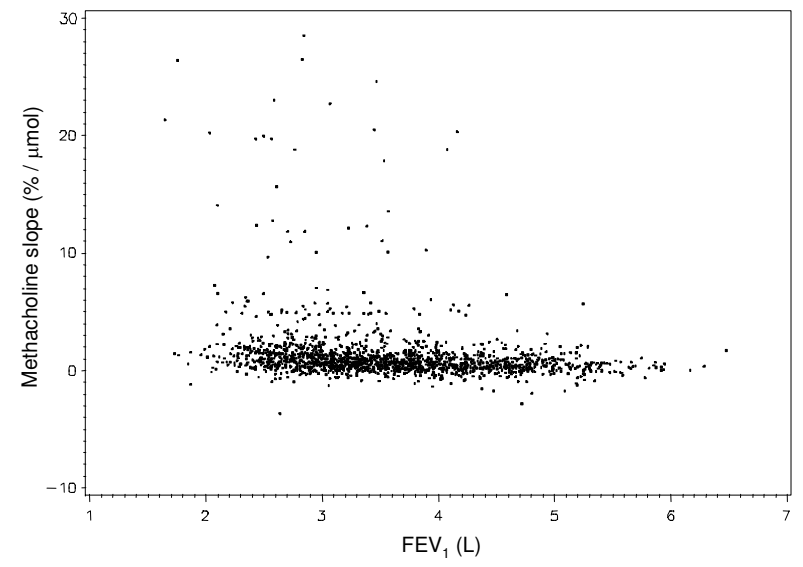

Figure 2

Scatter plot of methacholine slope vs. pretest level of FEV, for our study sample $(n=1567)$ (excluding 5 observations with slopes $>30 \% / \mu \mathrm{mol})$

(49.4\%), explained by their lower prevalence of current or former smoking. A scatter plot of methacholine slope vs. baseline $\mathrm{FEV}_{1}$ (all subjects) is given in Figure 2.

Prediction equations of $95^{\text {th }}, 90^{\text {th }}, 75^{\text {th }}$ and $50^{\text {th }}$ percentiles of the two-point slope are given in Table 3 . The corresponding curves for 40 years old subjects are represented in Figure 3. Prediction equations were derived involving age and pre-test (or baseline) $\mathrm{FEV}_{1}$. Between the lower and upper quartile of $\mathrm{FEV}_{1}$, these models are of the form: $\mathrm{a}+\mathrm{b}^{*}$ Age $+\mathrm{c}^{*} \mathrm{FEV}_{1}+\mathrm{d}^{*} \mathrm{FEV}_{1}{ }^{2}$, whereas no quadratic term in $\mathrm{FEV}_{1}$ is used below the $1^{\text {st }}$ and above the $3^{\text {rd }}$ quartile. We thus used natural quadratic splines with knots at the lower and upper quartiles of $\mathrm{FEV}_{1}$ to describe the dependency of percentiles of methacholine slope on baseline $\mathrm{FEV}_{1}$. Therefore, up to the first quartile of $\mathrm{FEV}_{1}$, each percentile curve of slope for a given age is described by a straight line. Another straight line describes the percentile curve for $\mathrm{FEV}_{1}$-values above the upper quartile. These two straight line segments are connected by a parabola segment in such a way that the transition between the different pieces is smooth. Although the coefficients a and c have to vary between the three intervals, the smoothness requirement imposes linear restrictions on them. On the other hand, the coefficient b has the same value everywhere, since the association between slope and age appeared to be approximately linear for all percentiles considered. Consequently, the curves for figure 3 would have to be shifted downward and upward for ages higher and lower than 40 years, respectively. The model shows that, with lower pre-test values of $\mathrm{FEV}_{1}$, level and spread of the percentiles increases. A horizontal line drawn at $\mathrm{y}=$ $2.39 \%$ decrease $/ \mu \mathrm{mol}$ represents the threshold commonly

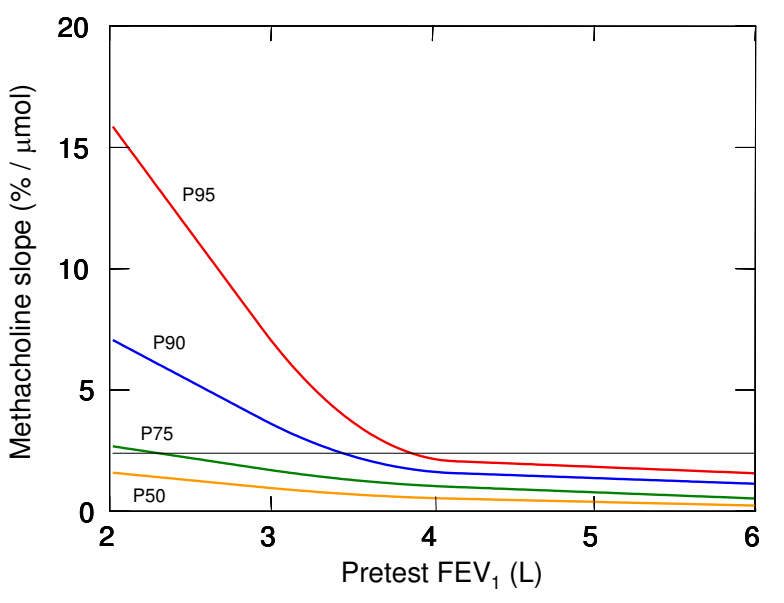

Figure 3

Percentiles of methacholine slope as a function of pretest level of FEV, (among persons of reference sample aged 40 years). This figure shows the percentiles of methacholine slope as a function of pretest level of FEV (among persons of reference sample aged 40 years). The horizontal line defines the threshold between "hyperreactive" and "normal" subjects as defined by a $20 \%$ fall of FEV, from the baseline value before or at the maximal methacholine dose. The scale of pretest level of FEV, extends from below the I st percentile to above the 99 th percentile of pretest level of $\mathrm{FEV}_{\mathrm{I}}$ in our reference sample.

used to define bronchial hyperreactivity (20\% decrease of $\mathrm{FEV}_{1}$ after a cumulative methacholine dose of $\leq 8.37$ $\mu \mathrm{mol})$. A higher proportion of subjects belong to this "hyperreactive" category at lower values of $\mathrm{FEV}_{1}$ or lower values of age. Consequently a higher proportion of women are defined as "hyperreactive" (Table 3). We provide an additional Excel file allowing calculation of the percentile of methacholine slope of a subject after introducing his/her age, pre-test $\mathrm{FEV}_{1}$, and results of methacholine challenge (i.e. methacholine total cumulative dose and percentage of $\mathrm{FEV}_{1}$ decline at this total cumulative dose) (Additional file 1).

Among subjects with physician-diagnosed asthma ( $\mathrm{n}=$ 411 ), the percentage of subjects with a fall of $20 \%$ or more during the methacholine test was significantly higher in women than in men $(58.8 \%$ vs. $43.8 \%$, p < 0.01$)$. In the same population, percentages of subjects above the $90^{\text {th }}$ percentile of methacholine slope from the model including $\mathrm{FEV}_{1}$ did not differ between both sexes $(51.0 \%$ vs. $51.2 \%, \mathrm{p}=0.98)$.

\section{Discussion}

Previous studies have demonstrated that non-specific bronchial responsiveness to methacholine may be influenced by a number of factors $[2,5,11-19]$. On the basis of 
Table 3: Percentiles of methacholine slope* among men and women of the reference sample, SAPALDIA cross-sectional study, I99 I

\begin{tabular}{|c|c|c|c|c|c|c|c|c|c|}
\hline & minimum & P5 & PIO & P25 & P50 & P75 & P90 & P95 & maximum \\
\hline $\begin{array}{l}\operatorname{men}(n= \\
612)\end{array}$ & -2.81 & -0.55 & -0.25 & 0.13 & 0.48 & 0.98 & 1.60 & 2.25 & 40.5 \\
\hline $\begin{array}{l}\text { women }(n= \\
955)\end{array}$ & -3.69 & -0.13 & 0.06 & 0.41 & 0.90 & 1.67 & 3.25 & 5.72 & 78.5 \\
\hline $\begin{array}{l}\text { entire } \\
\text { reference } \\
\text { sample }(n= \\
1567)\end{array}$ & -3.69 & -0.30 & -0.07 & 0.26 & 0.72 & 1.41 & 2.40 & 4.85 & 78.5 \\
\hline
\end{tabular}

* final \%decrease in FEV, from baseline divided by highest dose of methacholine administered

a review of the literature we excluded subjects presenting characteristics that may influence bronchial reactivity in a "non-physiological" way from our study population: smokers and former smokers, anamnestic asthmatic or bronchitic subjects, atopics, and persons who reported a recent respiratory infection. Moreover, the methacholine challenge was not performed in subjects with spirometric evidence of airway obstruction. Our preliminary analysis showed that among the potential predictor variables considered (i.e., sex, age, height, weight, $\mathrm{FEV}_{1}, \mathrm{FVC}, \mathrm{FEV}_{1}$ / FVC, $\left.\mathrm{FEF}_{25-75 \%}, \mathrm{FEF}_{25-75 \%} / \mathrm{FVC}\right)$, sex, age and either $\mathrm{FEV}_{1}$, $\mathrm{FEF}_{25-75 \%}$, or $\mathrm{FEF}_{25-75 \%} / \mathrm{FVC}$ had the strongest explanatory power (results not shown). Using pre-test $\mathrm{FEV}_{1}$ in addition to basic variables (sex, age, and height) improves prediction equations for methacholine reactivity, probably due to multiple factors. In subjects with restrictive syndrome, whatever the etiology, airway calibre is better described by absolute values of $\mathrm{FEV}_{1}$ than by the height or weight of subjects. Moreover, the underlying mechanisms of bronchial responsiveness to a pharmacological agent are complex and multifactorial. Several studies suggested that, apart from lung size, other important determinants of non specific bronchial hyperresponsiveness are airway geometry and properties of smooth muscles. Wassmer [15] showed in an adult German population that BHR (defined by a fall in $10 \%$ or $20 \%$ of $\mathrm{FEV}_{1}$ in methacholine challenge) or bronchial responsiveness (described by dose-response slope) is most strongly predicted by lung function parameters. In a study analyzing hyperreactivity in a large random adult population, Britton [16] showed that $\mathrm{FEV}_{1}, \mathrm{FEV}_{1}$ \%predicted and $\mathrm{FEV}_{1} / \mathrm{FVC}$ were strongly and independently related to BHR, identifying with varying degrees of overlap separate groups of individuals at increased risk of hyperreactivity. In our analysis, however, $\mathrm{FEV}_{1}$ / FVC was not significantly associated with methacholine slope. This may be explained by the exclusion of obstructive and atopic subjects.

An independent significant effect of age on bronchial methacholine dose-response slope is seen in our population study even after correction for $\mathrm{FEV}_{1}$, showing a negative cross-sectional association between slope and age after adjustment for differences in $\mathrm{FEV}_{1}$. This is an interesting result per se, given that an independent effect of age

Table 4: Estimated equations of the $95^{\text {th }}, 90^{\text {th }}, 75^{\text {th }}$ and $50^{\text {th }}$ percentiles of methacholine slope given age and pretest level of $F E V_{1}$ (litres), SAPALDIA cross-sectional study, 1991

\begin{tabular}{|c|c|c|c|c|c|c|c|c|c|c|c|c|}
\hline \multirow[t]{3}{*}{ Slope $_{95}$} & $=$ & 34.70 & - & 0.0167 & age & - & 9.001 & $\mathrm{FEV}_{\text {। }}$ & + & 0 & $\mathrm{FEV}_{1}{ }^{2}$ & $\left(\mathrm{FEV}_{1} \leq 2.93\right)$ \\
\hline & $=$ & 65.69 & - & 0.0167 & age & - & 30.152 & $\mathrm{FEV}_{\mathrm{I}}$ & + & 3.6095 & $\mathrm{FEV}_{1}{ }^{2}$ & $\left(2.93<\mathrm{FEV}_{1} \leq 4.14\right)$ \\
\hline & $=$ & 3.82 & - & 0.0167 & age & - & 0.266 & $\mathrm{FEV}_{\mathrm{I}}$ & + & 0 & $\mathrm{FEV}_{1}{ }^{2}$ & $\left(\mathrm{FEV}_{1}>4.14\right)$ \\
\hline \multirow[t]{3}{*}{ Slope $_{90}$} & $=$ & $|4.8|$ & - & 0.0160 & age & - & 3.523 & $\mathrm{FEV}_{\mathrm{I}}$ & + & 0 & $\mathrm{FEV}_{1}{ }^{2}$ & $\left(\mathrm{FEV}_{1} \leq 2.93\right)$ \\
\hline & $=$ & 26.48 & - & 0.0160 & age & - & I I.483 & $\mathrm{FEV}_{\mathrm{I}}$ & + & 1.3584 & $\mathrm{FEV}_{1}{ }^{2}$ & $\left(2.93<\mathrm{FEV}_{1} \leq 4.14\right)$ \\
\hline & $=$ & 3.19 & - & 0.0160 & age & - & 0.236 & $\mathrm{FEV}_{\mathrm{I}}$ & + & 0 & $\mathrm{FEV}_{1}{ }^{2}$ & $\left(\mathrm{FEV}_{1}>4.14\right)$ \\
\hline \multirow[t]{3}{*}{ Slope $_{75}$} & $=$ & 4.90 & - & 0.0056 & age & - & 0.997 & $\mathrm{FEV}_{\mathrm{I}}$ & + & 0 & $\mathrm{FEV}_{1}{ }^{2}$ & $\left(F E V_{1} \leq 2.93\right)$ \\
\hline & $=$ & 7.53 & - & 0.0056 & age & - & 2.796 & $\mathrm{FEV}_{\mathrm{I}}$ & + & 0.3071 & $\mathrm{FEV}_{1}{ }^{2}$ & $\left(2.93<\mathrm{FEV}_{1} \leq 4.14\right)$ \\
\hline & $=$ & 2.27 & - & 0.0056 & age & - & 0.253 & $\mathrm{FEV}_{\mathrm{I}}$ & + & 0 & $\mathrm{FEV}_{1}{ }^{2}$ & $\left(\mathrm{FEV}_{1}>4.14\right)$ \\
\hline \multirow[t]{3}{*}{ Slope $_{50}$} & $=$ & 3.03 & - & 0.0039 & age & - & 0.642 & $\mathrm{FEV}_{\mathrm{I}}$ & + & 0 & $\mathrm{FEV}_{1}{ }^{2}$ & $\left(\mathrm{FEV}_{1} \leq 2.93\right)$ \\
\hline & $=$ & 4.77 & - & 0.0039 & age & - & 1.828 & $\mathrm{FEV}_{\mathrm{l}}$ & + & 0.2025 & $\mathrm{FEV}_{1}{ }^{2}$ & $\left(2.93<\mathrm{FEV}_{1} \leq 4.14\right)$ \\
\hline & $=$ & 1.30 & - & 0.0039 & age & - & 0.152 & $\mathrm{FEV}_{\mathrm{I}}$ & + & 0 & $\mathrm{FEV}_{1}{ }^{2}$ & $\left(\mathrm{FEV}_{1}>4.14\right)$ \\
\hline
\end{tabular}


on BHR has not been consistently documented in the literature $[2,5,11-13,16]$.

Our percentile equations may be used in epidemiological studies to define more valid individual measures of responsiveness (i.e. severity) because they incorporate inherent confounding factors such as age and pre-test airway calibre. Moreover, the equations may enable clinicians to assess the degree of bronchial responsiveness in their patients with greater validity. We provide a simple Excel file enabling the computation of the percentile of a subject's bronchial responsiveness provided that this value lies between the $50^{\text {th }}$ and the $95^{\text {th }}$ percentile of the distribution in our adult reference population.

In clinical practice, methacholine challenge is currently used primarily to exclude asthma in atypical situations, being recognized as a useful but imprecise test. Using the $90^{\text {th }}$ percentile as a "cut-off" level for identifying asthmatics in our sample of subjects with self-reported physician diagnosed asthma provided a sensitivity of $51.1 \%$ which did not differ between sexes; this percentage was very similar to the percentage of subjects with a fall of $20 \%$ or more during the methacholine test in the same population $(50.9 \%)$, where a significant difference was, however, present between sexes $(58.8 \%$ in women vs. $43.8 \%$ in men). We therefore hypothesize that our equations and index provide a more valid individual marker of the clinical severity, enabling better characterization and quantification of bronchial responsiveness. While receiver operator characteristic (ROC) studies would be needed to evaluate the best "cut-off" percentile for asthma diagnosis, using the 90 th percentile yielded the same sensitivity in our subsample of asthmatics as the PD20 criterion in a similar study population of subjects with self-reported physician diagnosed asthma [30].

\section{Conclusion}

The present study provides equations for four relevant percentiles of methacholine slope (defined according to $\mathrm{O}^{\prime}$ Connor) depending on the age and baseline $\mathrm{FEV}_{1}$ in an adult reference population of non-obstructive and nonatopic persons. In addition to the fact that such models may help to better understand the underlying mechanisms of BHR, they may be of use in future epidemiological studies to better identify subjects whose bronchial hyperreactivity is caused by extrinsic factors or by obstructive or atopic conditions. It may be of interest to both clinicians and epidemiologists that the sensitivity of our method in identifying subjects with a doctor's diagnosis of asthma is the same in men and women whereas the traditional method based on PD20 has a lower sensitivity in men. More generally, our equations may help physicians to better characterize and follow bronchial responsiveness of individual patients, based on simple predictive factors.

\section{Competing interests}

The author(s) declare that they have no competing interests.

\section{Authors' contributions}

PYJ, CS and PL conducted the analyses and drafted the article. CS, NK, JPZ, OB, APP, RK, JS, UAL and PL contributed to the design of the study, the acquisition of data and the interpretation of data. All authors contributed to the conception of the research question, made important intellectual contributions during the drafting process and have given approval for the final version.

\section{Additional material}

\section{Additional File 1}

Calculation of percentiles of methacholine slope as a function of pretest $F E V_{1}$ and age. This additional Excel file allows calculation of the percentile of methacholine slope of a subject after introducing his/her age, pre-test $F E V_{1}$, and results of methacholine challenge (i.e. methacholine total cumulative dose and percentage of $F E V_{1}$ decline at this total cumulative dose).

Click here for file

[http://www.biomedcentral.com/content/supplementary/14659921-6-131-S1.xls]

\section{Acknowledgements}

Supported by grants from the National Research Program 26A (Grant No 4026-28099) of the Swiss National Science Foundation and from the Swiss Federal Office of Education and Science. SAPALDIA Basle is part of the European Respiratory Health Survey.

The authors wish to thank the SAPALDIA team fieldworkers at Aarau, Basle, Davos, Geneva, Lugano, Montana, Payerne and Wald. They are grateful to the collaborators of the central team at Basle (Institute of Social and Preventive Medicine), Lausanne (direction of the project) and Zurich (Allergology Unit, Department of Dermatology). They would like to thank $\mathrm{Dr}$ Sara Downs for commenting on the manuscript. The authors thank the authorities of the participating cantons of Aarau, Basle, Geneva, Vaud, Valais, Zurich, Ticino and Grisons for their logistic and financial support.

The SAPALDIA team includes: Ph. Leuenberger (P) (Study director), U. Ackermann-Liebrich (e) (Programme director), P. Alean (am), K. Blaser (a), G. Bolognini (p), J.P. Bongard (p), O. Brändli (p), P. Braun (p), C. Bron (l), M. Brutsche (I), C. Defila (m), G. Domenighetti (p), S. Elsasser (I), L. Grize (s), P. Guldimann (I), P. Hufschmid (I), W. Karrer (P), H. Keller-Wossidlo (o), R. Keller (p), N. Künzli (e), J.C. Lüthi (I), B.W. Martin (e), T. Medici (p), Ch. Monn (am), A.G. Peeters (pa), A.P. Perruchoud (p), A. Radaelli (I), Ch. Schindler (s), J. Schwartz (s), G. Solari (p), M.H. Schöni (p), J.M. Tschopp (p), B. Villiger (p), B. Wüthrich (a), J.P. Zellweger (p), E. Zemp (e). (a) : allergology; (am) : air pollution monitoring; (e) : epidemiology; (I) : local assistant; $(\mathrm{m})$ : meteorology; (o) : occupational medicine; (p) : pulmonology; (pa) : palynology; (s) : statistics.

\section{References}

I. Rogers DF, O'Connor BJ: Airway hyperresponsiveness: relation to asthma and inflammation? Thorax 1993, 48(II):1095-1096. 
2. Anto JM: Methods to assess and quantify BHR (bronchial hyperresponsiveness) in epidemiological studies. Clin Exp Allergy 1998, 28 Suppl I:13-4; discussion 32-6.

3. Savoy J, Junod AF: [Is non-allergenic bronchial hyperreactivity a good diagnostic test for asthma?]. Rev Mal Respir 1994, I I(2):20I-207.

4. Cockroft DW: Airway responsiveness. In Asthma Philadelphia Lippincott-Raven Publishers; 1997: 1253-1266.

5. Neukirch F, Cartier A: [Measure of bronchial hyperreactivity in epidemiology]. Rev Mal Respir 1994, I I (2): I0I-109.

6. O'Connor G, Sparrow D, Taylor D, Segal M, Weiss S: Analysis of dose-response curves to methacholine. An approach suitable for population studies. Am Rev Respir Dis 1987, 136(6): 14|2-14|7.

7. Banik AN, Holgate ST: Problems and progress in measuring methacholine bronchial reactivity. Clin Exp Allergy 1998, 28 Suppl I:15-9; discussion 32-6.

8. Cockcroft DW, Berscheid BA, Murdock KY: Unimodal distribution of bronchial responsiveness to inhaled histamine in a random human population. Chest 1983, 83(5):75I-754.

9. Cerveri I, Bruschi C, Zoia MC, Zanon P, Maccarini L, Grassi M, Rampulla C: Distribution of bronchial nonspecific reactivity in the general population. Chest 1988, 93(I):26-30.

10. Lockhart A, Malo JL: [Bronchial hyperreactivity. Definitions and history]. Rev Mal Respir 1994, II (2):85-92.

II. Bakke PS, Baste V, Gulsvik A: Bronchial responsiveness in a Norwegian community. Am Rev Respir Dis 1991, I43(2):317-322.

12. Trigg CJ, Bennett JB, Tooley M, Sibbald B, D'Souza MF, Davies RJ: A general practice based survey of bronchial hyperresponsiveness and its relation to symptoms, sex, age, atopy, and smoking. Thorax 1990, 45(II):866-872.

13. Burney PG, Britton JR, Chinn S, Tattersfield AE, Papacosta AO, Kelson MC, Anderson F, Corfield DR: Descriptive epidemiology of bronchial reactivity in an adult population: results from a community study. Thorax 1987, 42(I):38-44.

14. Schwartz J, Schindler C, Zemp E, Perruchoud AP, Zellweger JP, Wuthrich B, Leuenberger P, Ackermann-Liebrich U: Predictors of methacholine responsiveness in a general population. Chest 2002, I 22(3):812-820.

15. Wassmer G, Jorres RA, Heinrich J, Wjst M, Reitmeir P, Wichmann $\mathrm{HE}$ : The association between baseline lung function and bronchial responsiveness to methacholine. Eur J Med Res 1997, 2(2):47-54.

16. Britton J, Pavord I, Richards K, Knox A, Wisniewski A, Wahedna I, Kinnear W, Tattersfield A, Weiss S: Factors influencing the occurrence of airway hyperreactivity in the general population: the importance of atopy and airway calibre. Eur Respir J 1994, 7(5):881-887.

17. O'Connor GT, Sparrow D, Segal MR, Weiss ST: Smoking, atopy, and methacholine airway responsiveness among middleaged and elderly men. The Normative Aging Study. Am Rev Respir Dis 1989, I 40(6): 1520-1526.

18. Leuenberger P, Schindler C, Schwartz J, Ackermann-Liebrich U, Tara D, Perruchoud AP, Wuthrich B, Zellweger JP, Blaser K, Bolognini G, Bongard JP, Brandli O, Domenighetti G, Elsasser S, Grize L, Karrer W, Keller R, Kunzli N Medici T, Schoni MH, Solari G, Tschopp JM, Villiger $B$, Zemp E: Occupational exposure to inhalative irritants and methacholine responsiveness. Scand J Work Environ Health 2000, 26(2): $146-152$.

19. Zellweger JP, Fitting JW: [Ventilatory function and bronchial responsiveness in army recruits]. Schweiz Med Wochenschr 1990 I 20(40): | 466-| 472 .

20. Brandli O, Schindler C, Kunzli N, Keller R, Perruchoud AP: Lung function in healthy never smoking adults: reference values and lower limits of normal of a Swiss population. Thorax 1996, 5 I (3):277-283.

21. Brandli O, Schindler C, Leuenberger PH, Baur X, Degens P, Kunzli N, Keller R, Perruchoud AP: Re-estimated equations for 5 th percentiles of lung function variables. Thorax 2000, 55(2): $173-174$.

22. Martin BW, Ackermann-Liebrich U, Leuenberger P, Kunzli N, Stutz EZ, Keller R, Zellweger JP, Wuthrich B, Monn C, Blaser K, Bolognini G, Bongard JP, Brandli O, Braun P, Defila C, Domenighetti G, Grize L, Karrer W, Keller-Wossidlo H, Medici TC, Peeters A, Perruchoud AP, Schindler C, Schoeni MH, Villiger B, et al.: SAPALDIA: methods and participation in the cross-sectional part of the Swiss
Study on Air Pollution and Lung Diseases in Adults. Soz Praventivmed 1997, 42(2):67-84.

23. Standardization of spirometry-- 1987 update. Statement of the American Thoracic Society. Am Rev Respir Dis 1987, I36(5): 1 285-1298.

24. Kunzli N, Ackermann-Liebrich U, Keller R, Perruchoud AP, Schindler C: Variability of FVC and FEVI due to technician, team, device and subject in an eight centre study: three quality control studies in SAPALDIA. Swiss Study on Air Pollution and Lung Disease in Adults. Eur Respir J 1995, 8(3):37I-376.

25. Quadrelli S, Roncoroni A, Montiel G: Assessment of respiratory function: influence of spirometry reference values and normality criteria selection. Respir Med 1999, 93(8):523-535

26. Burney PG, Luczynska C, Chinn S, Jarvis D: The European Community Respiratory Health Survey. Eur Respir J 1994, 7(5):954-960.

27. Koenker R, Basset G: Regression quantiles. Econometrica 1978 , 46:33-50.

28. Hastie TJ, Tibshirani RJ: Generalized additive models. In Monographs on statistics and applied probability 43 Chapman \& Hall/CRC; 1990.

29. Yu K, Lu.Z., Stander J: Quantile regression:applications and current research areas. The Statistician 2003, 52:33I-350.

30. Lewis SA, Weiss ST, Britton JR: Airway responsiveness and peak flow variability in the diagnosis of asthma for epidemiological studies. Eur Respir J 200I, 18(6):92I-927.
Publish with Biomed Central and every scientist can read your work free of charge

"BioMed Central will be the most significant development for disseminating the results of biomedical research in our lifetime. "

Sir Paul Nurse, Cancer Research UK

Your research papers will be:

- available free of charge to the entire biomedical community

- peer reviewed and published immediately upon acceptance

- cited in PubMed and archived on PubMed Central

- yours - you keep the copyright

Submit your manuscript here:

http://www.biomedcentral.com/info/publishing_adv.asp
BioMedcentral 